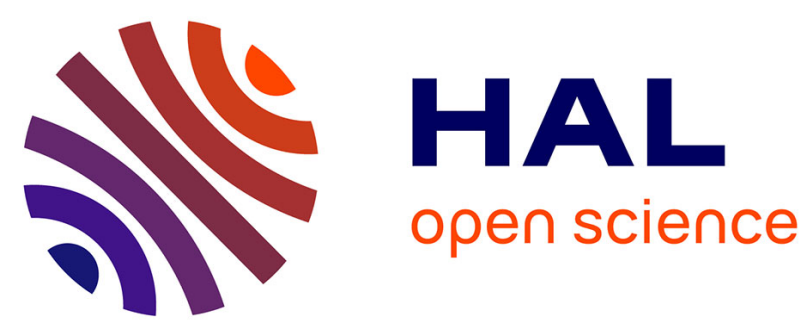

\title{
Do partners of severely disabled elderly protect against nursing home entry? Evidence from a French cohort
}

Louis Arnault, Jean-François Dartigues, Catherine Helmer, Karine Pérès, Jérôme Wittwer

\section{- To cite this version:}

Louis Arnault, Jean-François Dartigues, Catherine Helmer, Karine Pérès, Jérôme Wittwer. Do partners of severely disabled elderly protect against nursing home entry? Evidence from a French cohort. The Journal of the Economics of Ageing, 2020, 15, pp.100207 -. 10.1016/j.jeoa.2019.100207 . hal03489245

\section{HAL Id: hal-03489245 \\ https://hal.science/hal-03489245}

Submitted on 21 Dec 2021

HAL is a multi-disciplinary open access archive for the deposit and dissemination of scientific research documents, whether they are published or not. The documents may come from teaching and research institutions in France or abroad, or from public or private research centers.
L'archive ouverte pluridisciplinaire HAL, est destinée au dépôt et à la diffusion de documents scientifiques de niveau recherche, publiés ou non, émanant des établissements d'enseignement et de recherche français ou étrangers, des laboratoires publics ou privés.

\section{(ㄷ)(1) $\$$}

Distributed under a Creative Commons Attribution - NonCommerciall 4.0 International 


\title{
Do partners of severely disabled elderly protect against nursing home entry? Evidence from a French cohort
}

\author{
Louis Arnault ${ }^{\mathrm{a}}$, Jean-François Dartigues ${ }^{\mathrm{b}}$, Catherine Helmer $^{\mathrm{c}}$, Karine Pérès ${ }^{\mathrm{d}}$, \\ Jérôme Wittwer ${ }^{\mathrm{e}}$
}

${ }^{a}$ University of Bordeaux, Inserm, Bordeaux Population Health Research Centre, UMR 1219, 146 rue Léo Saignat, 33076 Bordeaux, France. E-mail: louis.arnault@u-bordeaux.fr

${ }^{\mathrm{b}}$ University of Bordeaux, Inserm, Bordeaux Population Health Research Centre, UMR 1219, 146 rue Léo Saignat, 33076 Bordeaux, France. E-mail: jean-francois.dartigues@u-bordeaux.fr

${ }^{\mathrm{c}}$ University of Bordeaux, Inserm, Bordeaux Population Health Research Centre, UMR 1219, 146 rue Léo Saignat, 33076 Bordeaux, France. E-mail: catherine.helmer@u-bordeaux.fr

${ }^{\mathrm{d}}$ University of Bordeaux, Inserm, Bordeaux Population Health Research Centre, UMR 1219, 146 rue Léo Saignat, 33076 Bordeaux, France. E-mail: karine.peres@u-bordeaux.fr

${ }^{\mathrm{e}}$ University of Bordeaux, Inserm, Bordeaux Population Health Research Centre, UMR 1219, 146 rue Léo Saignat, 33076 Bordeaux, France. E-mail: jerome.wittwer@u-bordeaux.fr

Corresponding author: Louis Arnault, University of Bordeaux, Inserm, Bordeaux Population Health Research Centre, UMR 1219, 146 rue Léo Saignat, 33076 Bordeaux, France. E-mail: louis.arnault@u-bordeaux.fr. Phone: +33(0)140568142.

Ethics statement: The PAQUID study has been approved by the ethics committee of the Centre Hospitalo-Universitaire of Bordeaux and conformed to the principles embodied in the Declaration of Helsinki.

\section{Declarations of interest: None.}




\section{Abstract}

Background: This article will explore the ability of partners to prevent nursing home entry for their disabled relatives: does the role played by partners vary with age and the type of disability affecting the relatives they care for?

Methods: We used data from a French cohort study, which included 3777 seniors who were initially living in the community in two French districts (Gironde and Dordogne) and who were followed for 22 years, between 1989 and 2011. Three Cox competing risks models are estimated.

Results: The presence of a partner reduces the risk of nursing home admission by $40 \%$ for an elderly individual who is 80 years old. However, that protective effect of partners is no longer significant at the 5\% level when the elderly suffers from limitations in fundamental activities of daily-living or after the age of 84 when the individual is cognitively impaired.

Conclusions: The low protective effect of partners against the risk of nursing home entry for the oldest-old or severely disabled should lead to a reassessment of the relevance of informal support for this specific group of individuals.

\section{Keywords}

Informal caregivers; cohort study; cognitive impairments; duration model. 


\section{Introduction}

Encouraging in-home support for disabled elderly individuals may contribute to reducing the amount of public expenditures devoted to long-term care, while respecting the will of most of disabled elderly individuals to stay home if possible. Given an elderly individual's level of disability, community-based production of his level of functioning requires the receipt of long-term care as an input, either through formal home care purchased in the market or informal care provided by family members or relatives ${ }^{1}$. In each family, one determines the combination of formal home care and informal care that produces the optimal level of care, conditional on the disabled elderly remaining in the community. Then, one compares this option with the alternative of institutional care in a nursing home and chooses the care and associated living arrangement that maximize the overall satisfaction of family members. In this regard, informal care should play a crucial role in the decisions taken regarding a disabled individual's living arrangement.

Several circumstances may reduce the marginal productivity of informal caregivers and prevent them from providing community-based support for disabled elderly individuals. Helping a disabled relative frequently increases the risk of isolation ${ }^{2}$, raises the probability of declaring physical or psychological troubles ${ }^{3,4}$ and reduces labour market participation ${ }^{5-8}$ : consequently, it can favour nursing home admission. In this regard, from an economic policy perspective, it is crucial to understand the extent to which family members can support their disabled relative and help them to stay living in the community or, conversely, approve their nursing home admission.

In the literature dealing with the explanatory factors for nursing home admission, ${ }^{9-14}$ studies have specifically analysed the effects of informal care use. Several authors highlight a protective effect informal care use against the risk of nursing home entry. ${ }^{15,16}$ On the contrary, 
others do not observe any significant effect of the availability of informal caregivers on the future risk of nursing home entry ${ }^{17}$ or find that having children, i.e., potential informal caregivers, makes the protective effect of receiving formal home-care allowances against the risk of institutionalization vanish ${ }^{18}$.

Several reasons could explain these ambiguous results. First, the influence of informal care on the risk of nursing home entry strongly depends on the nature of the relationship between the disabled elderly individual and the caregiver. The presence of partners and children would have a crucial role against the risk of nursing home entry. ${ }^{19}$ In-home support of friends or neighbours may not be as protective. Second, receiving informal care reduces the risk of institutionalization unless the caregivers state that they are overburdened, in which case, the risk increases. ${ }^{20}$

In this study, we would like to bring new insights into the role of informal care on the risk or nursing home entry. We focus the analysis on the protective role of partners against nursing home entry for their disabled relatives. Looking at the production function of communitybased care for disabled elderly individuals, we aim in one sense to study the variations of the marginal productivity of informal care provided by partners over the distribution of care recipient morbidity (physical and mental) through its impact on the disabled individuals' living arrangements. Taking advantage of a cohort study that included elderly individuals living in the community in two French districts and who were followed for a very long period of 22 years, we can estimate reliable effects of the partner's presence on the risk of nursing home entry, according to the disability type and the age. To our knowledge, it is the first article dealing with this topic and using such a long-term high-quality cohort study. This article delivers robust quantitative results that help better understanding the influence of a partner presence on care arrangements for disabled or cognitively impaired elderly individuals, in a longitudinal perspective. 


\section{Methods}

\section{Data}

We conducted survival analyses of the timing of first nursing home admissions that occurred between 1988 and 2011. Our sample was drawn from the PAQUID study, ${ }^{21}$ which is a longterm cohort started in 1988 that focused on analysing brain and functional ageing over time. The sample consists of 3777 individuals who are 65 years old or older and who were initially living in the community. It is representative of elderly community residents of Gironde and Dordogne, which are two districts in Southwest France. Seventy-five geographic units or municipalities were randomly chosen (thirty-seven in Gironde and thirty-eight in Dordogne) and a three-step random procedure on the electoral rolls stratified upon age, sex and size of the geographic unit led to 5,554 elderly individuals living at home (4,050 in Gironde and 1,504 in Dordogne). Among the selected elderly individuals, 2792 initially living in Gironde accepted to participate to the study and 985 initially living in Dordogne. The data were collected at the home of participants during a face-to-face interview with a neuropsychologist. The data collected at baseline were related to the socio-economic and demographic situations of the participants as well as their objective and subjective health status, their cognitive performance and disabilities, and the care they receive. The participants were tested again one year after baseline (only those living in Gironde) and then 3, 5, 8, 10, 13, 15, 17, 20 and 22 years after.

\section{Nursing home entry}

The main event of interest in this study is the first entry into a nursing home. Every individual living in a nursing home (with or without medical facilities), with a host family or in a longstay institution for the elderly, is considered to be institutionalized. Death (in the community) 
can prevent some elderly individuals from being institutionalized: it is a competing event that we must account for when analysing nursing home entry. Additionally, because some individuals in our sample are not perfectly observed until one of these two competing events occurs, several observations are censored. Censoring comes in many forms: any entries into a nursing home occurring after the end of our observation period, i.e. after 2011, are not observed. It also occurs when observations are terminated for reasons that are not under the control of the investigator of PAQUID. Some elderly individuals may move out of Gironde or Dordogne and it may be impossible to contact them. Other people may refuse to participate in the study after several years, because of health conditions or disability for instance.

Table 1 - Nursing home entry, death at home and censoring during the follow-up period of the PAQUID cohort

\begin{tabular}{ccccc}
\multirow{2}{*}{$\begin{array}{c}\text { Years after } \\
\text { baseline }\end{array}$} & \begin{tabular}{c} 
Number of individuals \\
\cline { 2 - 5 }
\end{tabular} & Institutionalized $\left(\%^{\mathrm{a}}\right)$ & $\begin{array}{c}\text { Dead } \\
\mathrm{n}\left(\%^{\mathrm{a}}\right)\end{array}$ & $\begin{array}{c}\text { Censored } \\
\mathrm{n}\left(\%^{\mathrm{a}}\right)\end{array}$ \\
\hline 0 & Not applicable & Not applicable & Not applicable & 3777 \\
3 & $175(4.6)$ & $445(11.8)$ & $527(14.0)$ & 2630 \\
5 & $88(3.3)$ & $229(8.7)$ & $131(5.0)$ & 2182 \\
8 & $93(4.3)$ & $247(11.3)$ & $127(5.8)$ & 1715 \\
10 & $71(4.1)$ & $131(7.6)$ & $71(4.1)$ & 1442 \\
13 & $68(4.7)$ & $239(16.6)$ & $85(5.9)$ & 1050 \\
15 & $42(4.0)$ & $138(13.1)$ & $49(4.7)$ & 821 \\
17 & $55(6.7)$ & $121(14.7)$ & $33(4.0)$ & 612 \\
20 & $39(6.4)$ & $114(18.6)$ & $36(5.9)$ & 423 \\
22 & $27(6.4)$ & $87(20.6)$ & $33(7.8)$ & 276 \\
\hline Total: $0-22$ & $658\left(17.4^{\mathrm{b}}\right)$ & $1751\left(46.4^{\mathrm{b}}\right)$ & $1092\left(28.9^{\mathrm{b}}\right)$ & $276\left(6.8^{\mathrm{b}}\right)$ \\
\hline
\end{tabular}

${ }^{\text {a }}$ Among all individuals still at risk at period $\mathrm{t}-1$.

${ }^{\mathrm{b}}$ Among the 3777 individuals at risk at baseline.

Table 1 displays the housing situations of the individuals in our sample during the follow-up period. The event "nursing home entry" occurred only for 658 individuals, which represents $17.4 \%$ of the initial sample. Additionally, 1751 individuals ( $46.3 \%$ of the initial sample) "died 
at home" during the follow-up period. Finally, 1368 individuals were alive at home and censored at their last follow-up screening: among them, 276 were still alive in the community 22 years after baseline.

\section{Explanatory variables of interest}

Our explanatory variables of interest are those that measure the disability level of the participants and the care they received. Using data from the PAQUID survey, a hierarchic scale of disability based on limitations in mobility, activities of daily-living (ADL, including bathing, dressing, using the toilet, going to/ going out of the bed, and feeding) and instrumental activities of daily-living (IADL, including using the phone, grocery shopping, using transportation, taking medications and managing a budget) has been built and validated. ${ }^{22}$ The hierarchic scale of disability goes from 0 to 3 according to the type of limitations from which the individuals suffer. The first two modalities ("no restriction" and "mobility disorders only") are gathered together because the number of individuals having no limitations in mobility decreases very quickly with age.

The cognitive skills of participants were measured using the Mini-Mental State Examination (MMSE). ${ }^{23}$ The MMSE evaluation is a 30-point test that is dedicated to measure the global cognition of an individual. The cut-off point of 24 is usually chosen by practitioners to distinguish between people with normal cognitive functioning and cognitively impaired individuals. As specific attention is paid to intellectual functioning in the PAQUID survey, a series of other procedures have been realized to diagnose cases of dementia. Psychometric tests have been made to evaluate visual memory (Benton's Visual Retention Test), verbal memory (Wechsler's Paired-Associates), verbal fluency (Isaacs Set Test), visuospatial attention (Zazzo), and simple logical reasoning (Digit Symbol Test). After the psychometric evaluation, the psychologists completed systematically a standardized 
questionnaire allowing determination of the criteria for dementia: subjects who met the criteria were evaluated by a neurologist. This stage also included complementary exams if accepted by the general practitioners and the subject (CT scanner or magnetic resonance imaging for instance). A consensus conference was eventually held by a body of experts in order to classify each case definitively ${ }^{21}$. Even if our goal is not to focus exclusively on people suffering from dementia, we do not want to miss any of them when measuring cognitive disorders. Consequently, we use both the MMSE score and the diagnosis of dementia to build a dichotomous variable that indicates whether the participant has normal cognitive functioning (MMSE score greater or equal to 25 and no diagnosis of dementia) or cognitive disorders (MMSE score lower or equal to 24 or diagnosis of dementia).

The last group of variables of interest are those that measure formal home care and informal care, which are the two main inputs for the community-based production of an elderly individual's level of functioning conditional on his disability level. Although they are available in the data, we do not introduce the variables measuring the effective use of formal (or informal) care into the models because they would be endogenous. The receipt of home care may be positively correlated with unobservable (health) characteristics that increase the risk of institutionalization ${ }^{15}$. To address this issue, we choose to introduce all factors at our disposal that are assumed to be exogenous and associated with the disabled individual's ability to purchase formal care in the market on the one hand (level of education, former occupation, income tax payment and main housing occupancy status at baseline), or his probability of receiving informal care from a family member, on the other hand. In our models, we estimate the effect of the presence of potential informal caregivers on the risk of nursing home admission. Having potential informal caregivers may impact the risk of nursing home entry through two main channels, that we do not aim to disentangle in this article: either via the effective supply of informal care they provide or irrespectively of whether informal 
care is effectively provided (only because these potential caregivers exist or because they correlate with other unobserved characteristics that are associated with the risk of nursing home entry). Several binary indicators introduced into the models account for the presence of potential informal caregivers, including having alive children at baseline, having at least one alive daughter, having at least one family member living in the same region and living with a partner. Close attention is paid to the partner, who is likely to be the main informal caregiver if he or she lives under the same roof.

\section{Empirical strategy}

The Cox competing risks model is especially suited to our topic of interest. ${ }^{24,25}$ This model enables us to account for death that competes with the risk of nursing home entry, and censoring. The Cox competing risks model also considers the time-evolution of several factors that could potentially explain the risk of institutionalization, such as health status or the presence of a partner. Such explanatory factors that vary over time are designated by the (T) symbol in the tables of results.

Two main assumptions are made for estimating a Cox competing risks model: as in a standard Cox model, the censoring mechanism has to be noninformative. It means that the censoring of an observation should not provide any information regarding the prospects of nursing home entry or death of that particular unit beyond the censoring time, conditional on the covariates. In other words, measured covariates have to fully account for the potential association between dropout and nursing home entry (and between dropout and death). The second assumption is very similar to the first one but specific to the Cox competing risks model: conditional on the covariates, those who are at particularly high (or low) risk of nursing home entry are no more (or less) likely to experience the competing event of death. Again, measured covariates, such as health and disability variables for instance, have to fully account 
for the potential association between nursing home entry and death. In this regard, data from the PAQUID survey are especially rich concerning the variables that measure the respondents' health and disability status.

Under these assumptions, the partial likelihood of a competing risks model (described in Appendix) is separable into a product of partial likelihoods with each one being associated with a specific risk. Thus, even if both competing risks are dependent (they are only assumed to be independent conditional on the covariates), it is possible to maximise each part of the partial likelihood separately. Because we are mainly interested in the explanatory factors of nursing home entry in this article, we only estimate the coefficients associated with the instantaneous risk of "nursing home admission" (and not the coefficients related to the competing risk of death) and treat the deceased individuals as censored observations. Under the assumptions made, the estimates reported are the effects of covariates on the instantaneous risk of nursing home entry (for an individual alive and still living in the community).

Three models are specified in this article. In the first one, we separately introduce a set of variables related to the disability level and variables measuring the presence of informal caregivers. We aimed to measure the respective impacts on the risk of nursing home admission. In the second model, we make the presence of a partner interact with the index of disability. In the third specification, we make the presence of a partner interact with the variable measuring the cognitive skills. The purpose of these last two models is to observe whether the protective effect of a partner against nursing home admission differs according to the type and severity of troubles.

In the Cox competing risks models, the effects of the explaining variables on the instantaneous risk of nursing home entry are assumed to be time-invariant. The Schönfeld residuals test leads us to reject this hypothesis for both the presence of a partner and the 
variables measuring the level of disability (i.e., hierarchic index of disability and cognitive functioning). Consequently, interactions between these variables and the age of the participants are introduced in our three models to account for the various effects over time.

\section{Results}

\section{Descriptive statistics}

In Table 2, we display the average values at baseline of the main available factors in PAQUID that are likely to explain nursing home admission. These average values are computed for three subsamples of individuals. Those who entered a nursing home during the period of observation ( $\mathrm{N}=658)$, those who "died at home" during the follow-up period $(\mathrm{N}=1751)$ and those censored at their last follow-up screening $(\mathrm{N}=1368)$. Three variables were analysed that measured the supply of informal care potentially received by the individuals at baseline. According to Table 2, the individuals admitted to a nursing home have significantly less living children at baseline compared to individuals who died in the community on average (pvalue of the t-test between $\mathrm{NH}$ and $\mathrm{D}$ strictly lower than 0.001$)$ : they had 1.76 children alive on average against 1.94 for those who died in the community.

Individuals who have a living daughter and who are living with a partner at baseline are significantly underrepresented among people who entered a nursing home: $41.3 \%$ of individuals admitted to an institution had a partner at baseline against $58.8 \%$ of individuals who died at home. Overall, $28.7 \%$ of individuals who died in the community did suffer from limitations in mobility and in instrumental activities of daily living (HIER=2) at baseline against $32.9 \%$ of those who entered a nursing home. We observe a similar gap but with an opposite trend (6.6\% against $4.3 \%)$ among elderly individuals suffering from limitations in ADL at baseline $(\mathrm{HIER}=3)$. Concerning cognition, individuals who have cognitive 
impairments at baseline are significantly overrepresented among the group of people who entered an institution ( $27.0 \%$ versus $22.6 \%$ of individuals deceased in the community).

Regarding the other control variables, the results from Table 2 indicate that health outcomes at baseline (except depressive symptoms) were not significantly different between those admitted to an institution and those deceased in the community. Individuals who pursued further study (16.0\% against $21.0 \%$ of deceased individuals), who were former executives (15.7\% against $25.5 \%)$ and who paid the income tax $(42.0 \%$ against $47.2 \%)$ are underrepresented among individuals who entered a nursing home. The same result is observed for men: they only correspond to $23.1 \%$ of institutionalized individuals, whereas they represent $50.9 \%$ of elderly individuals who died in the community.

Censored individuals had different characteristics at baseline from those of individuals who entered a nursing home: they were more frequently men $(39.0 \%$ against $23.1 \%$ of those who entered a nursing home) and significantly younger individuals (73.4 at baseline against 77.0 for those institutionalized). Former executives and homeowners are overrepresented among censored observations. Censored individuals had significantly more children alive at baseline on average (2.03 against 1.76 for those who entered a nursing home), and they more often had a daughter alive and lived with a partner $(59.9 \%$ of censored individuals lived with a partner against $41.3 \%$ of those who entered an institution). They were in better health and less frequently disabled than those who entered a nursing home. Consequently, those who dropped out would have had a lower risk of nursing home entry (or death) that the individuals still participating: we could expect their time of occurrence for the events "nursing home entry" or "death" to be significantly higher than the average time, if they were still observable (informative censoring). It is very important to measure and include in the model these covariates that are likely to affect the rate of censoring. 
Table 2 - Sample characteristics of the PAQUID cohort at baseline

\begin{tabular}{|c|c|c|c|c|c|}
\hline Variables & $\begin{array}{c}\text { Entered a } \\
\text { nursing home } \\
(\mathrm{NH})^{\mathrm{a}}\end{array}$ & Dead (D) ${ }^{b}$ & $\begin{array}{l}\text { Censored } \\
\qquad(\mathrm{C})^{\mathrm{c}}\end{array}$ & $\begin{array}{l}\text { T-test for } \\
\text { equality } \\
\text { of means } \\
\text { between } \\
\text { NH \& D }\end{array}$ & $\begin{array}{c}\text { T-test for } \\
\text { equality } \\
\text { of means } \\
\text { between } \\
\text { NH \& C }\end{array}$ \\
\hline $\begin{array}{l}\text { Individuals living in Gironde (vs. } \\
\text { Dordogne) }\end{array}$ & 0.719 & 0.709 & 0.788 & & $* * *$ \\
\hline Age & 77.0 & 76.5 & 73.4 & & $* * *$ \\
\hline Men $^{d}$ & 0.231 & 0.509 & 0.390 & $* * *$ & $* * *$ \\
\hline Individuals who pursued further study ${ }^{\mathrm{d}}$ & 0.160 & 0.210 & 0.237 & $* * *$ & $* * *$ \\
\hline $\begin{array}{l}\text { Former workers / housewives / non- } \\
\text { working }{ }^{\mathrm{d}}\end{array}$ & 0.316 & 0.236 & 0.311 & $* * *$ & \\
\hline $\begin{array}{l}\text { Former executives / intellectuals } \\
\text { /craftspeople / shop owners }{ }^{\mathrm{d}}\end{array}$ & 0.157 & 0.255 & 0.225 & $* * *$ & $* * *$ \\
\hline Individuals paying income tax ${ }^{\mathrm{d}}$ & 0.420 & 0.472 & 0.538 & $* *$ & $* * *$ \\
\hline Homeowners ${ }^{d}$ & 0.594 & 0.636 & 0.664 & & $* * *$ \\
\hline HIER $=1$ (no limitation or mobility only) ${ }^{d}$ & 0.628 & 0.647 & 0.802 & & $* * *$ \\
\hline HIER $=2$ (mobility and IADL only) ${ }^{d}$ & 0.329 & 0.287 & 0.176 & $* *$ & $* * *$ \\
\hline HIER $=3$ (mobility, IADL and ADL) ${ }^{d}$ & 0.043 & 0.066 & 0.022 & $* *$ & $* *$ \\
\hline Individuals with cognitive disorders ${ }^{\mathrm{d}}$ & 0.270 & 0.226 & 0.196 & $* *$ & $* * *$ \\
\hline Individuals with depressive symptoms ${ }^{d}$ & 0.187 & 0.142 & 0.111 & $* * *$ & $* * *$ \\
\hline $\begin{array}{l}\text { Individuals with a very good or a good } \\
\text { health status }{ }^{d}\end{array}$ & 0.412 & 0.448 & 0.528 & & $* * *$ \\
\hline Individuals with signs of a stroke ${ }^{d}$ & 0.064 & 0.071 & 0.033 & & $* * *$ \\
\hline $\begin{array}{l}\text { Individuals with signs of an angina or a } \\
\text { heart attack }\end{array}$ & 0.217 & 0.245 & 0.172 & & $* *$ \\
\hline Number of living children & 1.76 & 1.94 & 2.03 & $* *$ & $* * *$ \\
\hline $\begin{array}{l}\text { Individuals with at least one living } \\
\text { daughter }^{d}\end{array}$ & 0.524 & 0.591 & 0.609 & $* * *$ & $* * *$ \\
\hline Individuals living with a partner ${ }^{\mathrm{d}}$ & 0.413 & 0.588 & 0.599 & $* * *$ & $* * *$ \\
\hline
\end{tabular}

${ }^{\mathrm{a}} \mathrm{n}=1751 .{ }^{\mathrm{b}} \mathrm{n}=658 .{ }^{\mathrm{c}} \mathrm{n}=1368$.

d Indicator variable: $1=$ yes, $0=$ no.

$* * \mathrm{p} \leq 0.05$; *** $\mathrm{p} \leq 0.01$ (t-test for equality of means between the two groups, robust to unequal variances). 
Table 3 - Cox models: factors associated with the risk of nursing home entry (Hazard Ratios)

\begin{tabular}{|c|c|c|c|}
\hline Variable & Model 1 & Model 2 & Model 3 \\
\hline \multicolumn{4}{|l|}{ Socio-economic situation } \\
\hline Lives in Gironde (Ref: Dordogne) & 0.95 & 0.95 & 0.95 \\
\hline Men (Ref: women) & $\mathbf{0 . 7 8} * *$ & $\mathbf{0 . 7 8 * *}$ & $\mathbf{0 . 7 8} * *$ \\
\hline \multicolumn{4}{|l|}{ Level of education (Ref: None) } \\
\hline Primary school & 1.11 & 1.11 & 1.12 \\
\hline Secondary school or more & 0.98 & 0.98 & 0.99 \\
\hline \multicolumn{4}{|l|}{ Former occupation (Ref: Employees) } \\
\hline Farmers & $0.75 * *$ & $0.75^{* * *}$ & $0.75 * *$ \\
\hline Workers / Housewives / Non-working & 1.14 & 1.14 & 1.14 \\
\hline Executives / Intellectuals /Craftspeople / Shop owners & $0.74 * *$ & $0.74 * *$ & $0.74 * *$ \\
\hline Pays income tax (Ref: No) & 1.04 & 1.04 & 1.04 \\
\hline \multicolumn{4}{|l|}{ Main housing (Ref: Tenant) } \\
\hline Owner & 0.83 & 0.84 & 0.83 \\
\hline Rent-free / Other & $0.65 * * *$ & $0.65 * * *$ & $0.65 * * *$ \\
\hline \multicolumn{4}{|l|}{ Health and disability } \\
\hline \multicolumn{4}{|l|}{ (T) Self-assessed health (Ref: Fair) } \\
\hline Very good or Good & 0.93 & 0.93 & 0.93 \\
\hline Bad or Very bad & 1.06 & 1.06 & 1.07 \\
\hline \multicolumn{4}{|l|}{ (T) Limitations (Ref: None or mobility only) } \\
\hline Mobility and IADL & $7.07 * * *$ & $6.38 * * *$ & $7.25 * * *$ \\
\hline Mobility, IADL and ADL & $47.7 * * *$ & $33.5 * * *$ & $48.3 * * *$ \\
\hline \multicolumn{4}{|l|}{ (T) Limitations \# Age of participant } \\
\hline Mobility and IADL \# Age & $0.94 * * *$ & $0.94 * * *$ & $0.94 * * *$ \\
\hline Mobility, IADL and ADL \# Age & $0.87 * * *$ & $0.88 * * *$ & $0.87 * * *$ \\
\hline \multicolumn{4}{|l|}{ (T) Cognitive functioning (Ref: Normal) } \\
\hline Cognitive disorders & $4.32 * * *$ & $4.31 * * *$ & $4.84 * * *$ \\
\hline \multicolumn{4}{|l|}{ (T) Cognitive functioning \# Age of participant } \\
\hline Cognitive disorders \# Age & $0.96 * * *$ & $0.96 * * *$ & $\mathbf{0 . 9 5} * * *$ \\
\hline (T) Depressive symptoms (Ref: No) & $1.29 * *$ & $1.29 * *$ & $1.28 * *$ \\
\hline (T) Experienced strokes (Ref: No) & 1.05 & 1.04 & 1.05 \\
\hline (T) Experienced angina or heart attack (Ref: No) & 1.02 & 1.02 & 1.02 \\
\hline (T) Receiving treatment against diabetes (Ref: No) & 0.85 & 0.85 & 0.85 \\
\hline \multicolumn{4}{|l|}{ Potential supply of informal care } \\
\hline Has a family member living in the same region (Ref: No) & 0.97 & 0.97 & 0.97 \\
\hline Number of living children & $0.94 * *$ & $0.94 * *$ & $0.94 * *$ \\
\hline Has a least one living daughter (Ref: No) & $0.81 * *$ & $\mathbf{0 . 8 1} * *$ & $0.81 * *$ \\
\hline (T) Lives with a partner (Ref: No) & $0.37 * * *$ & $0.32 * *$ & 0.50 \\
\hline (T) Lives with a partner \# Age of participant & $1.04 * *$ & 1.04 & 1.02 \\
\hline Interaction: Partner \& Limitations & $\mathrm{No}^{\mathrm{a}}$ & Yes $^{\text {a }}$ & $\mathrm{No}^{\mathrm{a}}$ \\
\hline Interaction: Partner / Limitations / Age & No ${ }^{\text {a }}$ & Yes $^{\text {a }}$ & $\mathrm{No}^{\text {a }}$ \\
\hline Interaction: Partner \& Cognitive functioning & $\mathrm{No}^{\mathrm{a}}$ & No ${ }^{\text {a }}$ & Yes ${ }^{\text {a }}$ \\
\hline Interaction: Partner / Cognitive functioning / Age & $\mathrm{No}^{\text {a }}$ & $\mathrm{No}^{\text {a }}$ & Yes ${ }^{\text {a }}$ \\
\hline Number of observations & 3015 & 3015 & 3015 \\
\hline
\end{tabular}

${ }^{a}$ As Hazard Ratios of interaction terms cannot be interpreted easily, they are not reported here $* * \mathrm{p} \leq 0.05 ; * * * \mathrm{p} \leq 0.01$. 


\section{Effect of socio-economic characteristics on the risk of nursing home entry}

The results of the Cox models 1,2 and 3 are provided in Table 3. Several socio-economic characteristics of the elderly individuals in the sample have an impact on their risk of institutionalization. According to model 1, the risk of nursing home admission is much lower for men than for women with all other things being equal $(H R=0.78)$. The result certainly emphasizes that the life expectancy of men is shorter compared to women and that men have a greater probability of dying before experiencing disability problems that would require nursing home admission. Being a former executive rather than a former employee reduces the hazard of nursing home entry by $26 \%(H R=0.74)$. It may suggest that former executives are more reluctant to live in an institution and have enough income and assets for to finance housing adjustments or professional home care. Being a homeowner rather than tenant reduces the instantaneous risk of nursing home admission by $17 \%$, even if this effect is significant at the $10 \%$ level only $(\mathrm{HR}=0.83)$. Homeowners might be more emotionally attached to their housing or face obstacles when trying to sell it, especially in rural areas. The potential conflicts between future heirs or the considerable amounts of out-of-pocket expenditures for the housing in most French nursing homes may also discourage owners more than the tenants from entering an institution. Similarly, living or staying rent-free delays the nursing home entry of the respondents significantly $(H R=0.65)$ : this result can be interpreted as a first clue in support of a protective effect of informal care against the risk of institutionalization because living rent-free raises the probability of being helped by a coresident.

\section{Effect of disability on the risk of nursing home entry}

According to Figure 1, the instantaneous risk of nursing home entry at each age (before 87) increases significantly with the hierarchical scale of disability. This risk is multiplied by 2.8 
for an 80-year-old individual with limitations in both mobility and IADL, and it is increased by 6.2 for the same individual who is also limited in performing ADL.

Figure 1 - Effect of limitations on the instantaneous risk of nursing home entry according to age.

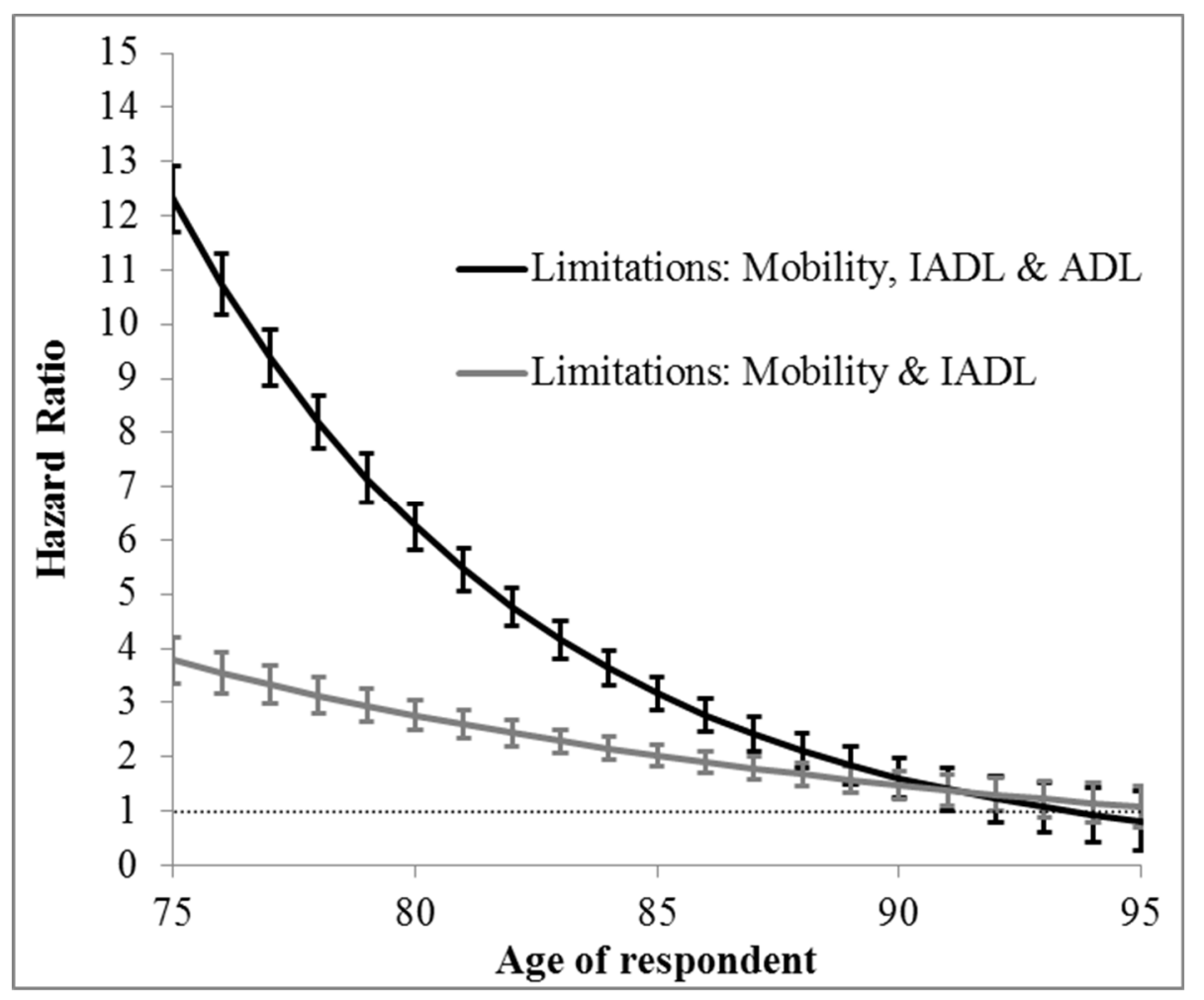

The $y$ axis indicates the estimated ratio of hazards of nursing home entry between the group of individuals with limitations in both mobility and IADL and the group of individuals with no limitations or limitations in mobility only (grey curve) and the estimated ratio of hazards of nursing home entry between the group of individuals with limitations in both mobility, IADL \& ADL and the group of individuals with no limitations or limitations in mobility only (black curve). Estimates stem from model 1. N=3015 participants who are observed at several survey waves and whose data at baseline are complete. Confidence intervals at the $5 \%$ level are represented by vertical bars.

The existence (or the occurrence) of cognitive disorders significantly increases the risk of nursing home admission too. According to Figure 2, the instantaneous risk of institutionalization is multiplied by 2.4 when an 80 -year-old individual suffers from cognitive impairments. Even if activity restrictions and cognitive disorders increase the instantaneous 
risk of institutionalization significantly, the magnitude decreases with age to such an extent that the effect is close to being not significant after an age of 90 is reached. Several explanations for this result are worth considering. The older the respondents become, the more the risk of nursing home entry for the control group (i.e., the individuals without any restriction) increases, which consequently tends to reduce the value of the relative risks that are displayed. In addition, cognitive disorders and activity restrictions may have a greater impact on the risk of institutionalization of younger seniors compared to the oldest seniors. At the oldest ages, feeling isolated in the community might become the main driver of nursing home admission for disabled elderly individuals. This age effect may also emphasize a selection effect. The eldest individuals who still live in the community despite strong activity restrictions or cognitive impairments would be those whose environment is especially favourable for in-home support. Finally, one should keep in mind that only individuals with a stable level of disability remain on the same age-decreasing curve. In fact, the level of disability of individuals tends to increase with age, which translates graphically into "jumps" from the lowest curve to the highest and increases the risk of nursing home entry. 
Figure 2 - Effect of cognitive impairments on the instantaneous risk of nursing home entry according to age.

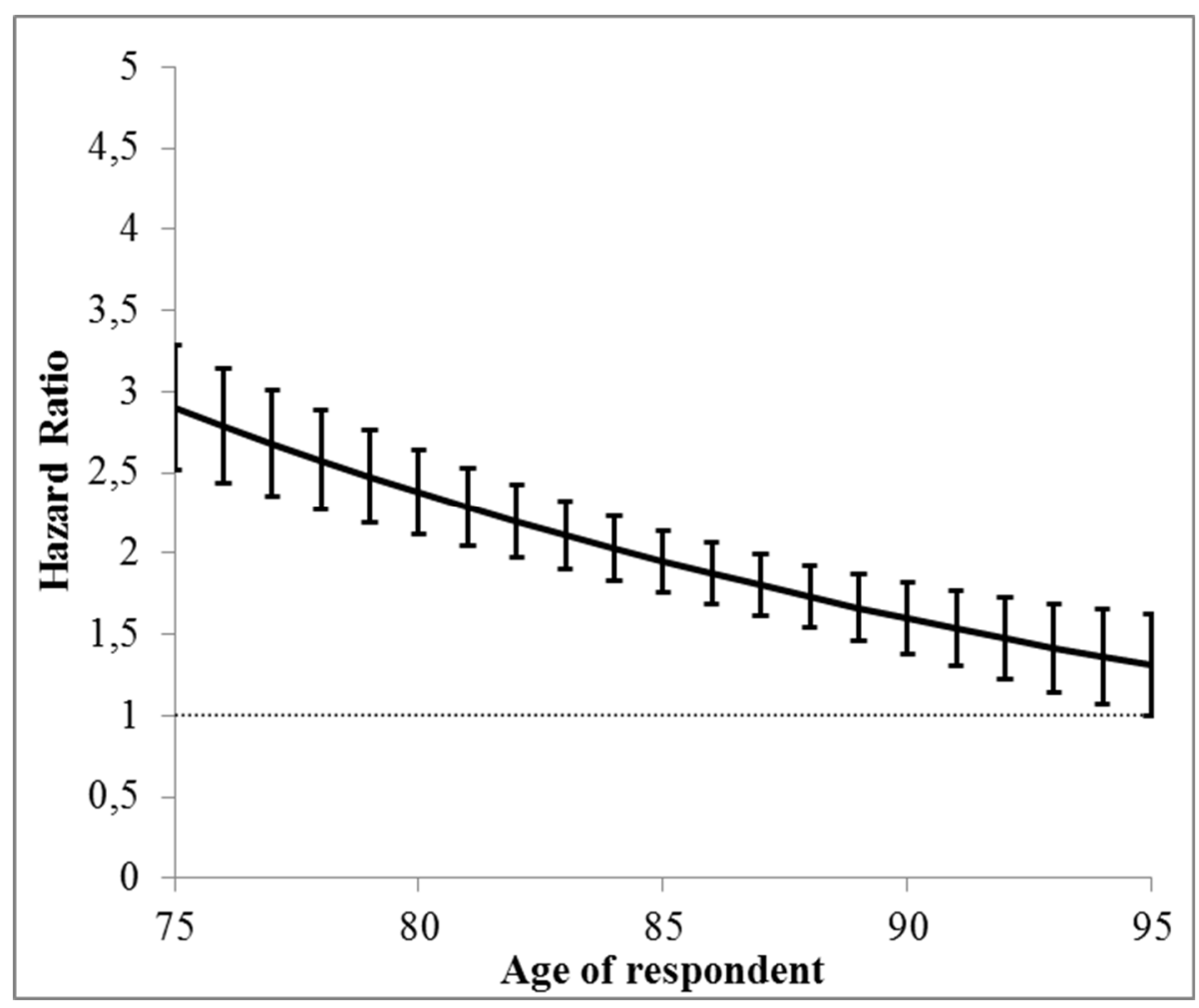

The y axis indicates the estimated ratio of hazards of nursing home entry between the group of individuals suffering from cognitive impairments and the group of the others. Estimates stem from model 1. $\mathrm{N}=3015$ participants who are observed at several survey waves and whose data at baseline are complete. Confidence intervals at the $5 \%$ level are represented by vertical bars.

\section{Effect of children and daughters on the risk of nursing home entry}

Having children, and especially daughters as social norms of caring have traditionally been gendered, has been proved to be strongly associated with informal care provision. ${ }^{5,15,16,26}$ According to model 1 (Table 3), each living child reduces significantly the hazard of nursing home entry by $6 \%$ on average $(H R=0.94)$. Additionally, having at least one living daughter reduces the instantaneous risk of nursing home admission by $19 \%(H R=0.81)$ for a given number of living children. On the contrary having a family member living in the same region does not significantly reduce the risk of nursing home entry. 


\section{Effect of partners on the risk of nursing home entry}

Figure 3 provides the impact of partners over time, according to model 1 . The presence of a partner reduces the risk of nursing home admission by $40 \%$ for an elderly individual who is 80 years old. The Hazard Ratio is significantly lower than 1 (at the 5\% level) until the age of 87, which means that a partner has a protective effect against nursing home admission. However, this effect tends to disappear after the age of 87.

Figure 3 - Effect of the presence of a partner on the instantaneous risk of nursing home entry according to age.

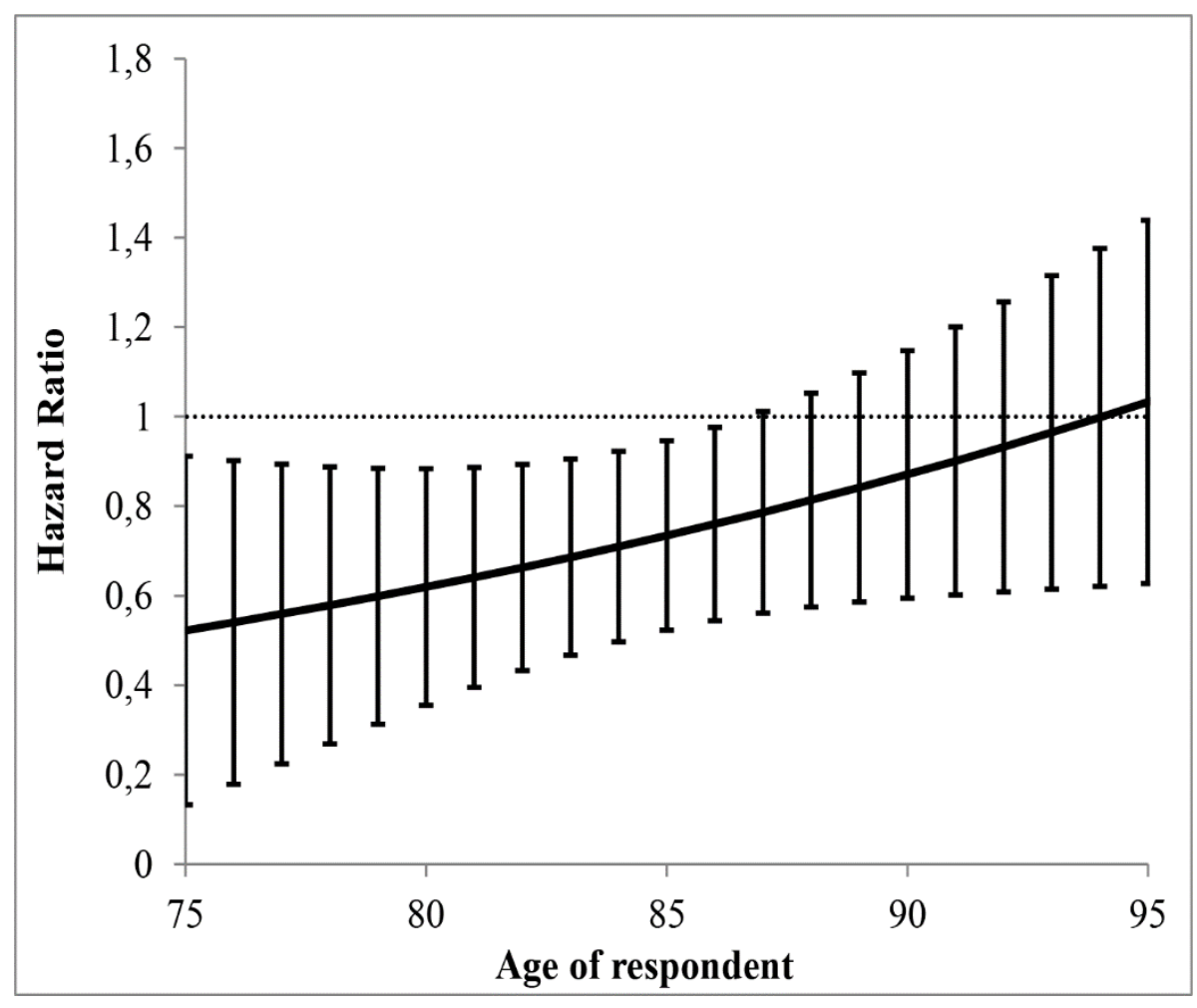

The $y$ axis indicates the estimated ratio of hazards of nursing home entry between the group of individuals living with a partner and the group of the others. Estimates stem from model 1. N=3015 participants who are observed at several survey waves and whose data at baseline are complete. Confidence intervals at the $5 \%$ level are represented by vertical bars.

According to Figure 4, obtained thanks to the model 2, living with a partner has a strong and significant protective effect (at the 5\% level) against the nursing home entry of people who do 
not suffer from any limitation (or from mobility disorders only) before the age of 87 . Indeed, it reduces their instantaneous risk of nursing home entry by $45 \%(H R=0.55)$ at the age of 80 .

Figure 4 - Effect of the presence of a partner on the instantaneous risk of nursing home entry according to age and type of limitation.

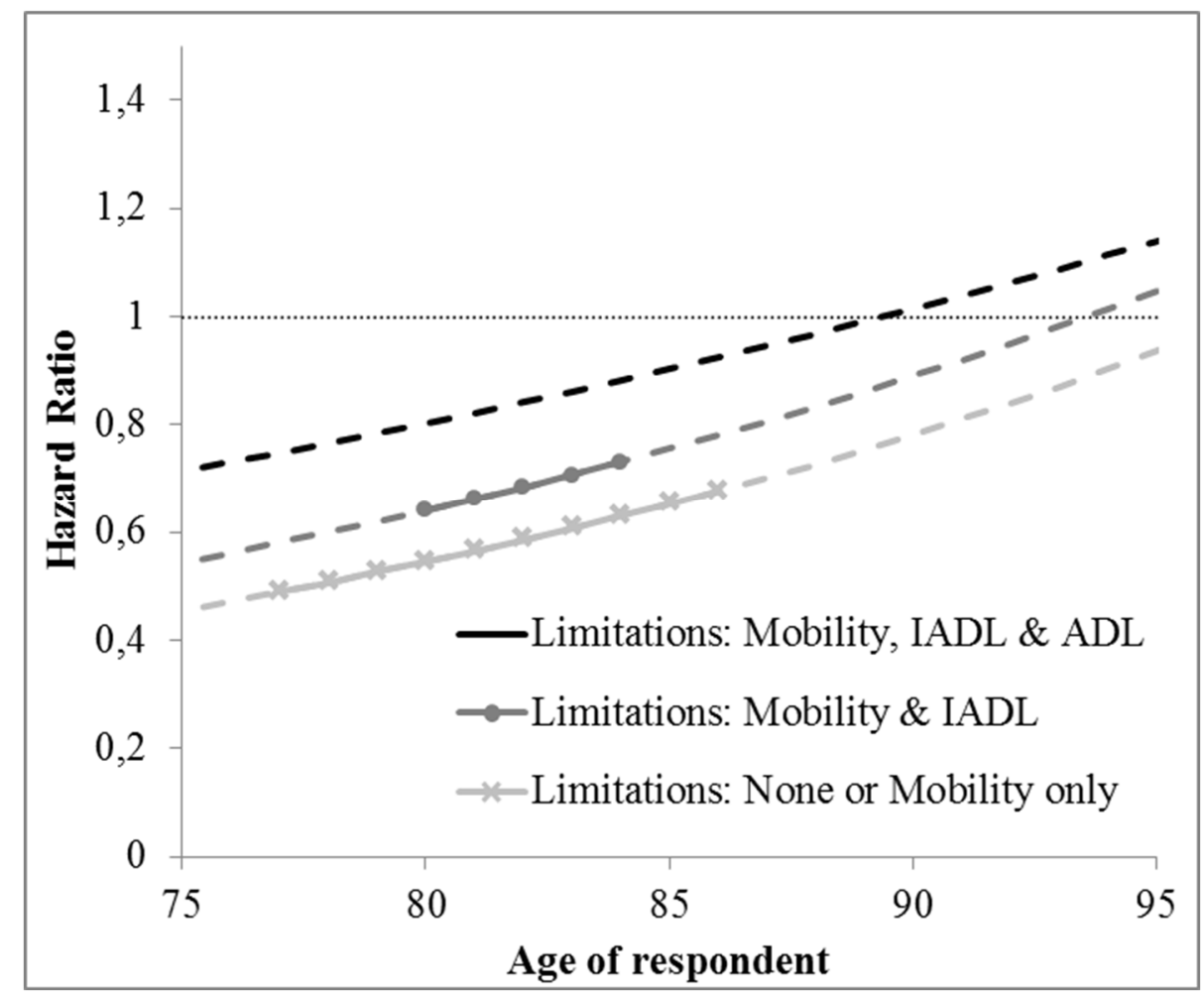

The y axis indicates the estimated ratio of hazards of nursing home entry between the group of individuals living with a partner and the group of persons with no partner. Three curves are displayed according to the type of limitation. Estimates stem from model 2. $\mathrm{N}=3015$ participants who are observed at several survey waves and whose data at baseline are complete. The Hazard Ratios that are significantly different from 1 (at the $5 \%$ level) are shown with a solid line.

When the participant suffers from both mobility and IADL limitations, the protective effect remains significant at the $5 \%$ level between 80 and 85 , even if its magnitude is smaller. Having a partner decreases their instantaneous risk of nursing home admission by $36 \%$ at an age of $80(H R=0.64)$. However, the protective effect of a partner is no longer significant at the $5 \%$ level ( $H R=0.80$ at the age of 80$)$ when the disabled elderly also suffers from limitations in ADL. 
Figure 5 shows the effect of partners on the instantaneous risk of nursing home admission according to the cognitive functioning of the participants at each age (according to model 3).

Figure 5 - Effect of having a partner on the instantaneous risk of nursing home entry at each age according to the level of cognitive functioning.

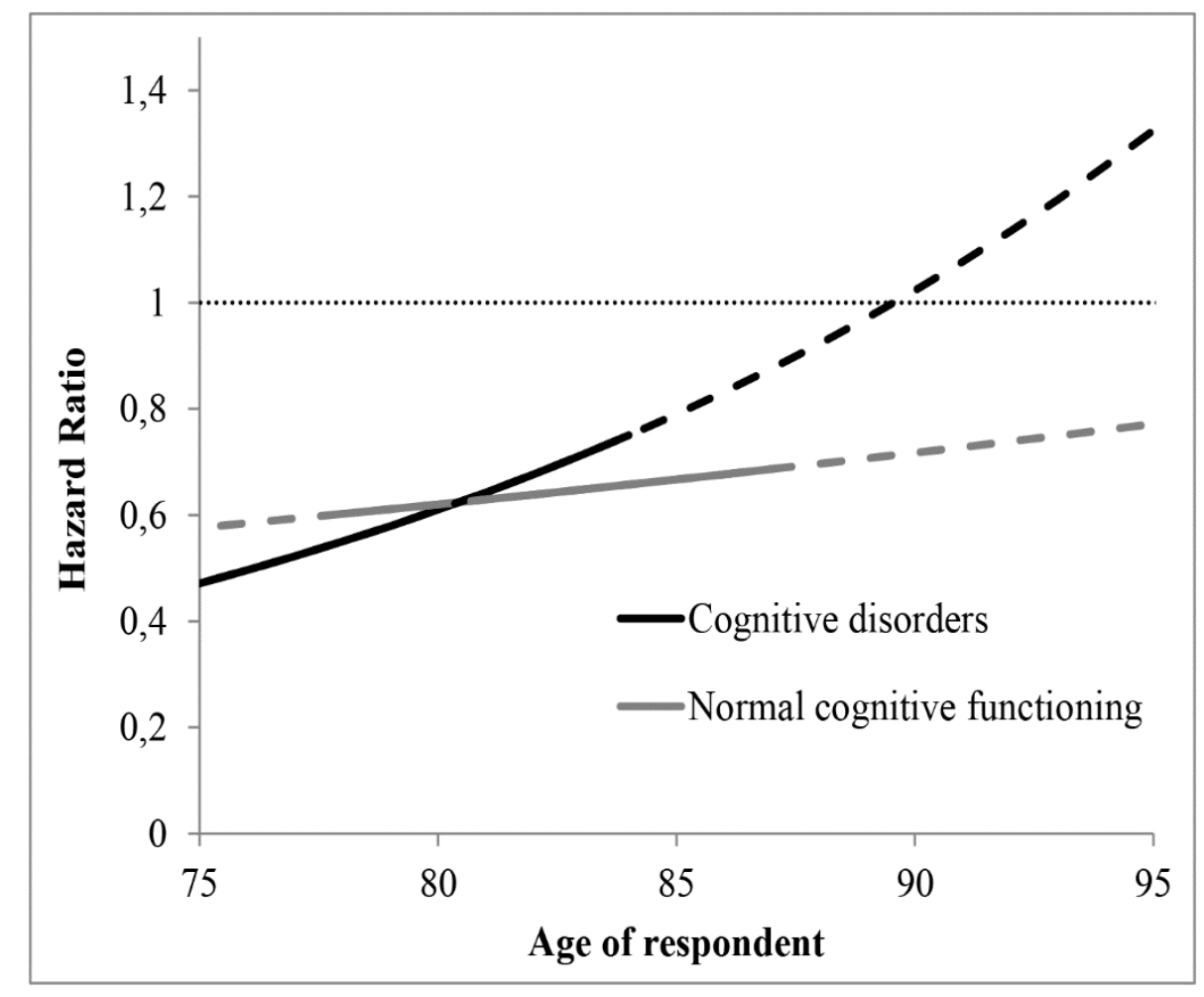

The y axis indicates the estimated ratio of hazards of nursing home entry between the group of individuals living with a partner and the group of persons with no partner. Two curves are displayed according to whether the disabled elderly suffers from cognitive disorders or not. Estimates stem from model 3. $\mathrm{N}=3015$ participants who are observed at several survey waves and whose data at baseline are complete. The Hazard Ratios that are significantly different from 1 (at the 5\% level) are shown with a solid line.

First, being in a couple has a strong and significant protective effect (at the 5\% level) against nursing home admission for cognitively impaired individuals until the age of 84 , and for individuals with normal cognitive functioning, a partner significantly reduces the instantaneous risk of institutionalization by $38 \%(\mathrm{HR}=0.62)$ at an age of 80 . Second, the protective effect of having a partner against the risk of institutionalization tends to decrease 
more quickly with age when the elderly individual's cognitive functioning is altered rather than normal. The protective effect of having a partner is no longer significant at the $5 \%$ level after the age of 84 , when the participant suffers from cognitive impairments, whereas it remains significant until 87 for individuals without cognitive disorders. As for severely disabled individuals (see Figure 4), the protective effect of partners against nursing home admission of cognitively impaired elderly individuals disappears with old age.

\section{Discussion}

The first objective of this study was to measure the impact of potential informal caregivers on the housing choices of French disabled elderly individuals. As expected, the presence of potential informal caregivers had a strong protective effect against the participants' risk of nursing home entry. Informal caregivers who were potentially available to provide in-home support, and especially partners, are among the most important stakeholders that enable their disabled relatives to stay in the community.

The other focus of this work was to analyse the variations of the impact of informal care provided by partners on care arrangements over the distribution of care recipient morbidity. In other words, we aimed to study the extent to which the role played by partners varied according to the type and severity of the disability affecting the relative they cared for. Our results indicate that the marginal productivity of informal care from partners decreases with the age of the disabled individuals and the severity of their disability, which in turn increases the risk of institutionalization. The protective effect of the partner against nursing home entry is preserved when the disabled elderly individual suffers from mobility limitations or limitations in instrumental activities of daily-living. In contrast, being in couple does not postpone the nursing home admission when the disabled individual suffers from limitations in fundamental activities of daily living (at all ages). We also observed a significant protective 
effect of partners against nursing home admission of "young" cognitively impaired individuals, which tends to vanish quickly after the age of 85. Partners of oldest-old individuals may have a greater likelihood to be affected by diseases or disability themselves. They could be less able to provide their increasingly disabled relative with informal care. Thus, encouraging in-home support for disabled elderly individuals in France is indirectly counting on potential informal caregivers to become involved, but their marginal productivity is attenuated at older ages or when their relatives are severely impaired.

The sample drawn from the PAQUID study is only representative of elderly community residents of Gironde and Dordogne and not of all French community residents aged 65 or more. The external validity of the results obtained remains subject to caution. Nevertheless, the 20-year mortality rate in the sample matches exactly the one observed in the French general population of the same age ${ }^{27}$. PAQUID also remains the only representative cohort of elderly people living at home in France, giving estimations of prevalence, incidence and duration of disability and Alzheimer disease and related disorders.

The validity of the Cox competing risks models estimated in this article depends on two main assumptions (noninformative censoring and conditional independence between the competing risks) that must be questioned. Some unobserved factors are likely to influence both the risk of nursing home entry and the risk of death in the community (or censoring). Some of the respondents might have been deceased or censored because of unobservable characteristics related to their living conditions, health or disability status for instance - that would have led them to institutionalization or prevented them from being institutionalized otherwise. An interesting extension of this article could be to implement alternative strategies for handling potentially informative censoring and conditional dependence, such as multi-state models. However, the specific need for considering the time-evolution of several factors that could 
potentially explain the risk of institutionalization led us to give priority to the Cox models in this study.

Because the successive survey periods occurred at intervals of two or three years, one might also argue that interval censoring should be accounted for in our models. Some individuals might have entered a nursing home and died in the interval between two consecutive periods. Additional research was performed 13 years after baseline to identify these individuals. Thus, around a hundred people among the 658 identified as having entered a nursing home during the follow-up period were found due to this additional work. As a robustness check, the Cox models were estimated again after reducing the follow-up period to 13 years after baseline (results not shown). The magnitude of the effects remains very similar to those obtained during a 22-year follow-up period.

The models used for this study also do not control for context variables related to the supply of long-term care in each district. Such variables likely evolved during the (long) follow-up period of a participant, and they might have influenced both specific risk of nursing home admission and the role of a partner against nursing home entry. We do not have at our disposal reliable measures of the supply of long-term care in each town of Gironde and Dordogne between 1988 and 2011. In addition, including them in our models would compel us to deal with strong endogeneity issues.

Similarly, we do not possess any reliable measure of the partner's health and disability status in the data from the PAQUID cohort. Yet, physical and psychological limitations may strongly reduce the ability of partners to cope with the disability of their relatives. The agedecreasing marginal productivity of informal care from partners may not only result from the increasing needs of disabled individuals but also, at a constant level of needs, from the lower ability of partners to meet them. The data does not enable us to favour one interpretation over 
the other. The effect of the partner's health status may also be partially captured by the other variables related to informal care receipt, such as having alive children or having at least one alive daughter. Children often start to provide their disabled parent(s) with a consequent amount of informal care as soon as their parent's partner is deceased or unable to provide care anymore. An area for future research would be to look at the effect of the characteristics of the caregiver herself (her age and health status) on nursing home entry of the elderly individuals.

Our estimates could also suffer from omitted-variable bias if we missed other important factors associated with both the disabled individual's probability of receiving informal care and the risk of nursing home entry. For instance, the data do not enable us to control for all variables related to the disabled individual's ability to purchase formal home care in the market, such as his household's income or the resources of his children. If income is negatively associated with both informal care use (assuming that formal and informal care are substitutes) and the risk of institutionalization, then omitting income may lead us to overestimate the protective effect of informal care against nursing home entry. We try to control for all factors at our disposal to attenuate this bias: level of education, former occupation, income tax payment and main housing occupancy status at baseline.

Despite these limitations, this article sheds light on the potential breaking points for partners providing care to their disabled relatives. At old age, the low protective effect of partners against the risk of nursing home entry should lead to a reassessment of the relevance of informal support for the oldest-old or severely disabled elderly. On the one hand, the low protective role of partners may reflect temporary issues that individuals are confronted with, such as a lack of technical skills or temporary (but unsatisfied) needs for respite. In that case, offering partners an opportunity to participate in more training sessions or providing them with more respite or formal home care could encourage them to keep become involved and 
increase their marginal productivity. On the other hand, the decreased protective role of partners with age or severe disability may also emphasize a partner's permanent discomfort or (physical and emotional) inability to handle severe troubles. Consequently, even if the wishes of the elderly to stay at home for as long as possible should be respected, our results question the global appropriateness of relying mostly on in-home family support for caring for old, severely disabled or cognitively impaired seniors.

Funding: One of the authors acknowledges generous support to his doctoral research provided by Fondation Médéric Alzheimer. 
Appendix - Likelihood of a competing risks model

For each of the $j=2$ competing risks described in the model (nursing home entry and death at home), it is possible to define a hazard function specific to each event:

$\forall j, \forall t, \lambda_{j i}(t)=\lambda_{\mathrm{j} 0}(t) \exp \left\{x_{j i}(t)^{\prime} \beta_{\mathrm{j}}\right\}$

The competing risk model specified below is semi-parametric because the baseline hazard functions specific to each event (the $\lambda_{\mathrm{j} 0}$ ) do not have to be explicit. The model is estimated by partial maximum likelihood ${ }^{25}$.

We assume that the $j$ risks are independent, conditional on the explanatory variables introduced in the model. Let $k_{j}$ be the number of individuals who have experienced the event $j$ and $T_{j 1}<\cdots<T_{j k_{j}}$ the $k_{j}$ dates of occurrence. The partial likelihood of the model is:

$L=\left[\prod_{i=1}^{k_{1}} \frac{\exp \left\{x_{1 i}\left(T_{1 i}\right)^{\prime} \beta_{1}\right\}}{\sum_{k \in R\left(T_{1 i}\right)} \exp \left\{x_{1 k}\left(T_{1 i}\right)^{\prime} \beta_{1}\right\}}\right]\left[\prod_{i=1}^{k_{2}} \frac{\exp \left\{x_{2 i}\left(T_{2 i}\right)^{\prime} \beta_{2}\right\}}{\sum_{k \in R\left(T_{2 i}\right)} \exp \left\{x_{2 k}\left(T_{2 i}\right)^{\prime} \beta_{2}\right\}}\right]$

,with $R\left(T_{j i}\right)$ representing the set of observations still at risk at time $T_{j i}$, which means the set of individuals $\mathrm{k}$ still observed at $\mathrm{T}_{\mathrm{ji}}$ who have not experienced events 1 or 2 (nursing home entry or death). The partial likelihood of a competing risks model is separable into a product of partial likelihoods with each one being associated with a specific risk. Thus, it is possible to maximise each part of the partial likelihood of the competing risks model separately, with no loss of statistical precision. Because we only focused on the explanatory factors of nursing home entry in this article, we only consider the event "nursing home admission" and estimate the $\beta_{1}$ vector separately by treating the deceased individuals as censored observations. 


\section{References}

1. Pezzin LE, Kemper P, Reschovsky J. Does publicly provided home care substitute for family care? Experimental evidence with endogenous living arrangements. J Hum Resour 1996; 650-676.

2. Levine NB, Gendron CE, Dastoor DP, et al. Existential issues in the management of the demented elderly patient. Am J Psychother 1984; 38: 215-223.

3. Coe NB, Van Houtven CH. Caring for mom and neglecting yourself? The health effects of caring for an elderly parent. Health Econ 2009; 18: 991-1010.

4. Llena-Nozal A, Mercier J, Tjadens F, et al. Help Wanted? OECD Publishing. Epub ahead of print 18 May 2011. DOI: 10.1787/9789264097759-en.

5. Ettner SL. The Impact of 'Parent Care' on Female Labor Supply Decisions. Demography 1995; 32: 63.

6. Ettner SL. The Opportunity Costs of Elder Care. J Hum Resour 1996; 31: 189.

7. Heitmueller A. The chicken or the egg? J Health Econ 2007; 26: 536-559.

8. Johnson RW, Lo Sasso AT. The Impact of Elder Care on Women's Labor Supply. Inq J Health Care Organ Provis Financ 2006; 43: 195-210.

9. Banaszak-Holl J, Fendrick AM, Foster NL, et al. Predicting nursing home admission: Estimates from a 7-year follow-up of a nationally representative sample of older Americans. Alzheimer Dis Assoc Disord 2004; 18: 83-89.

10. Gaugler JE, Kane RL, Kane RA, et al. Caregiving and Institutionalization of Cognitively Impaired Older People: Utilizing Dynamic Predictors of Change. The Gerontologist 2003; 43: 219-229.

11. Gaugler JE, Kane RL, Kane RA, et al. Early Community-Based Service Utilization and Its Effects on Institutionalization in Dementia Caregiving. The Gerontologist 2005; 45: $177-185$.

12. Gaugler JE, Duval S, Anderson KA, et al. Predicting nursing home admission in the U.S: a meta-analysis. BMC Geriatr; 7. Epub ahead of print December 2007. DOI: 10.1186/1471-2318-7-13.

13. Laferrère A, Van den Heede A, Van den Bosch K, et al. 22 Entry into institutional care: predictors and alternatives. In: Börsch-Supan A, Brandt M, Litwin H, et al. (eds) Active ageing and solidarity between generations in Europe. Berlin, Boston: DE GRUYTER. Epub ahead of print 14 January 2013. DOI: 10.1515/9783110295467.253.

14. Luppa M, Luck T, Weyerer S, et al. Prediction of institutionalization in the elderly. A systematic review. Age Ageing 2010; 39: 31-38.

15. Charles KK, Sevak P. Can family caregiving substitute for nursing home care? J Health 
Econ 2005; 24: 1174-1190.

16. Van Houtven $\mathrm{CH}$, Norton EC. Informal care and health care use of older adults. $J$ Health Econ 2004; 23: 1159-1180.

17. Ettner SL. THE EFFECT OF THE MEDICAID HOME CARE BENEFIT ONLONGTERM CARE CHOICES OF THE ELDERLY. Econ Inq 1994; 32: 103-127.

18. Muramatsu N, Yin H, Campbell RT, et al. Risk of Nursing Home Admission Among Older Americans: Does States' Spending on Home- and Community-Based Services Matter? J Gerontol B Psychol Sci Soc Sci 2007; 62: S169-S178.

19. Freedman VA. Family Structure and the Risk of Nursing Home Admission. J Gerontol B Psychol Sci Soc Sci 1996; 51B: S61-S69.

20. Jette AM, Tennstedt S, Crawford S. How Does Formal and Informal Community Care Affect Nursing Home Use? J Gerontol B Psychol Sci Soc Sci 1995; 50B: S4-S12.

21. Dartigues J-F, Gagnon M, Barberger-Gateau P, et al. The Paquid Epidemiological Program on Brain Ageing. Neuroepidemiology 1992; 11: 14-18.

22. Barberger-Gateau P, Rainville C, Letenneur L, et al. A hierarchical model of domains of disablement in the elderly: a longitudinal approach. Disabil Rehabil 2000; 22: 308-317.

23. Folstein MF, Folstein SE, McHugh PR. "Mini-mental state": a practical method for grading the cognitive state of patients for the clinician. J Psychiatr Res 1975; 12: 189198.

24. Cox DR. Regression Models and Life-Tables. J R Stat Soc Ser B Methodol 1972; 34: $187-220$.

25. Cox DR. Partial likelihood. Biometrika 1975; 62: 269-276.

26. Bonsang E. Does informal care from children to their elderly parents substitute for formal care in Europe? J Health Econ 2009; 28: 143-154.

27. Dartigues J-F, Helmer C, Letenneur L, et al. Paquid 2012: illustration and overview. Gériatrie Psychol Neuropsychiatr Vieil 2012; 10: 325-331. 